\title{
Automated Business Name Reservation and Registration System - A Case Study of Registrar General's Department, Ghana
}

\author{
Giovani Soglo \\ Faculty of Informatics, Ghana \\ Technology University College \\ PMB 100 Accra North \\ Accra, Ghana
}

\author{
Michael Osei Ntow \\ Faculty of Informatics, Ghana \\ Technology University College \\ PMB 100 Accra North \\ Accra, Ghana
}

\author{
Amevi Acakpovi \\ Department of \\ Electrical/Electronic, Accra \\ Polytechnic \\ P.O.Box: GP561 \\ Accra, Ghana
}

\begin{abstract}
Registering a business in Ghana has over the years been the greatest challenge of most entrepreneurs and investors, both local and expatriates. The current system in use at various branches of the Registrar General's Department do not synchronize properly with their central database and checking for redundancy of data takes a lot of time. This paper therefore seeks to develop an automated business name reservation and registration system which will provide a conducive mean of registering business in real time. Four main phases were involved in this project, namely planning phase, analysis phase, design phase, and implementation phase. The functionalities of the system are presented by UML diagrams that consist of a use case diagram and sequence diagram. A database was created with MySQL software to manage the registration process and an interactive web component was added to enable people to make reservations. The system was finally deployed at the Registrar General's Department of Ghana and evaluations show that it is very reliable, time saving and user friendly. It also provides extensive reporting and business intelligence.
\end{abstract}

\section{General Terms}

Database programming, UML diagram, Web application, human computer interaction

\section{Keywords}

Sequence diagram, use case diagram, user interface design, business registration, MySQL database.

\section{INTRODUCTION}

The Registrar General's Department which was established under the Ordinance in 1950 during the colonial era and became a department of the Ministry of Justice in 1961 and has the mandate of Government to ensure an efficient and effective administration of entities as well as the registration of businesses, industrial property, marriages, administration of estates and public trustees, to provide customer friendly services and accurate data for national planning [1].

Under the Registration of Business Names Act, 1962, business names must be registered with the Registrar of Business Names. However, the level of stress involved at the initial stages of getting a business name registered sometimes gets applicants frustrated. This problem is quite evident at the point where the applicant will have to check for availability of company name and obtain incorporation forms. The applicant must travel to the Registrar General's Department and present the proposed business name in order for a search to be conducted by a staff member to ascertain its availability. If available a reservation is made. Otherwise, the applicant will have to provide a new name for another search to be conducted.

The private sector has been recognized as the engine for growth and business registration has a key role to play in the private sector development. However, there is widespread public and international concern about the time it takes to register a business in Ghana, thereby prolonging the commencement of such businesses by both local and foreign investors. Some business ventures have been abandoned as a result of frustrations encountered during the registration and licensing processes.

Since 2003, the Government of Ghana has been thorough fully reviewing the registration and licensing regime for businesses with donor support. The strategy was, among others, aimed at ensuring efficiency in the business registration process.

Despite these efforts, a report by the World Bank, [2], titled "Doing Business" 2013, indicated that it takes approximately 64 days to start a business in Ghana. A section of the report that dealt with the topic "starting a business" did not rank Ghana, among the first 62 countries that they found it easy to start a business - a factor that will attract the attention of potential investors. Most of the issues indicated above could be overcome with the introduction of an automated business name reservation and registration system which will enable applicants to start the application process in the comfort of their homes before proceeding to the Registrar General's Department to continue with the registration process.

\section{PREVIOUS WORKS}

The establishment of Central Coordinating Registerfor Legal Entities implies considerable challenges mostlyrelated to the introduction of a unique identifier. Different authorities usevarious identifiers to link the information they needed to businesses. The World Bank Group [3] argues that, when the Register of Business Enterprises is established, the Register of Mortgaged Movable Property and the Register of Company Accounts mustmaintain an index linking the registered company name to a number in order to be able to perform name searches. Remarkably, this functionality is not provided by commerce registers despite the fact that they haveeven more urgent demand for it. Altinn, [3] ascertains that, when the Register of Business Enterprises is established, the name 
index must form the basis for allocating an identification number to registered businesses.Altinn stated that in 1991 the Register of Business Enterprise, Denmark, started allocating the organization number to businesses as a first step towards a unique identifier for legal entities.Hyllinge and lindgreen, [4] argues that implementing of Central Coordinating Register for Legal Entities must requirethat different registers of businesses had to be merged into one register of legal entities. Statistically, Denmark was responsible for that activity as it already had several sets of information on businesses. Based on this information, Statistics Denmark allocated the 9-digit organization number using the generator from the Central Coordinating Register for Legal Entities, which calculates the number in chronological order. The businesses then had to verify the related identifying information (name, address, type of activity).

A computerized central business, [5] was established in Norway and this brought to a big increase in the number of registered businesses. The Central Coordinating Register for Legal Entities, [5] stated that the number of processed cases within one hour, has increased steadily over the years. While the Register of Business Enterprises processed an average of 4.6 cases per hour in 2002, the average was 6.6 cases per hour in 2010 .

In 2012, [6], Australian Securities and Investments Commission (ASIC) started taking over the registration of business names from the states and territories. ASIC became responsible for registering, renewing and administering business names for all Australian businesses under the Business Names Registration Act 2011. However the system suffers some deficiencies including: delays in accessing the website for the business name register and in getting through to ASIC on the phone, delays in cancellation or transfer of business name, glitches on the business name register website and others. These types of problems have been largely discussed in related papers including [7-10]. Most of them tried to solve business registration problems from a software engineering perspective.

Despite all the efforts done to create a reliable computerized system for business registration, the registration system in Ghana is still manual and it is the objective of this paper to design a reliable one that automate it.

\section{METHODOLOGY}

An approach under the System Development Life Cycle (SDLC) which is the Waterfall approach has been adopted. Fig.1 depicts the waterfall sequence.

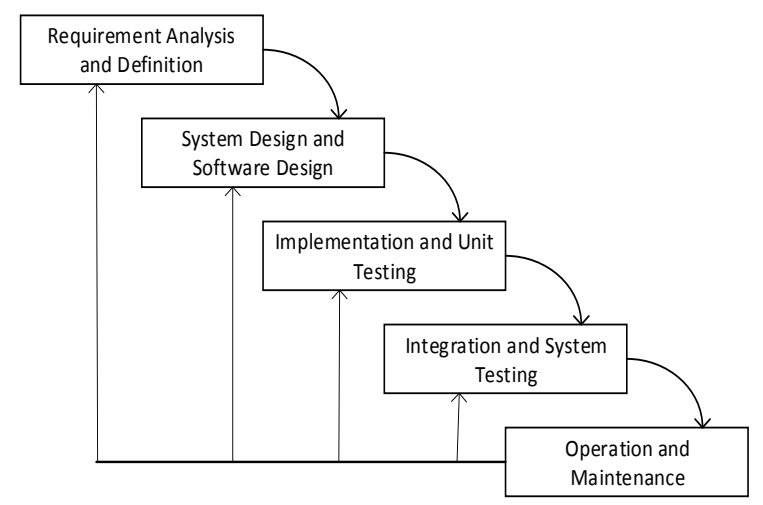

Fig1: Adopted waterfall model

This model, also referred to as a linear sequential life cycle model was chosen due to the fact that, it is straightforward, simple to understand and use, and the amount of resources required to implement this model are minimal.

\subsection{System Architecture}

A three-tier system architecture is employed. With this structure the business logic, the presentation (front-end) and the data storage area are put in separate layers. The system architecture defines how pieces of the application interact with each other, and what functionality each piece is responsible for performing.

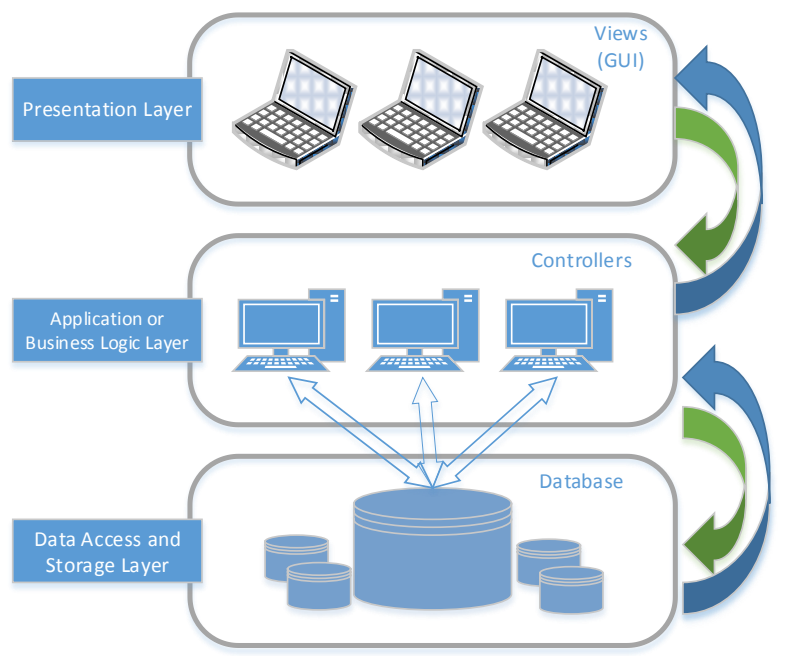

Fig 2: System Architecture of the automated business name reservation and registration system.

\subsection{System Design}

According to Dix and Zang, respectively [11] and [12] data structures and models used in developing effective system's architecture must follow three types of diagrams namely.

- Use Case Diagram

- $\quad$ Database model

- Sequence Diagram

These three diagrams have been used to design the data modelsand structures in this paper and the paragraphs below show their description.

\subsubsection{Use Case Diagram}

The use case diagram illustrated in figure 3 and figure 4, defines the interactions between external actors and the system under consideration.

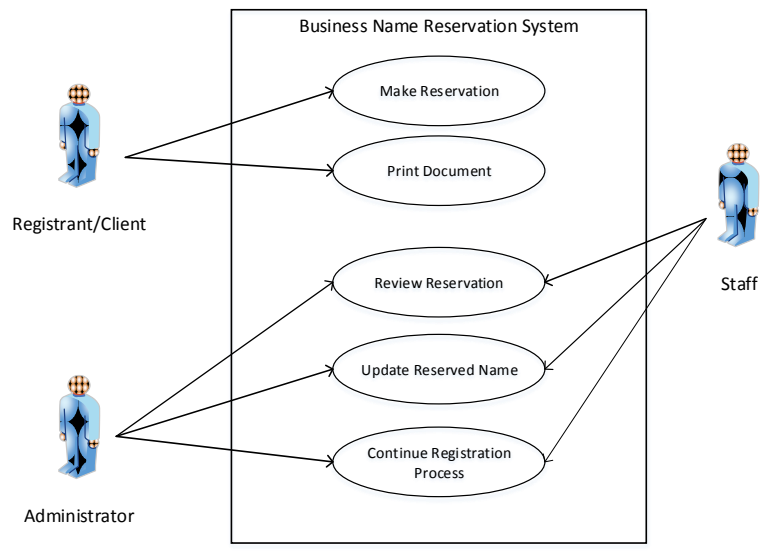

Fig 3: Use Case Diagram for Reservation System 


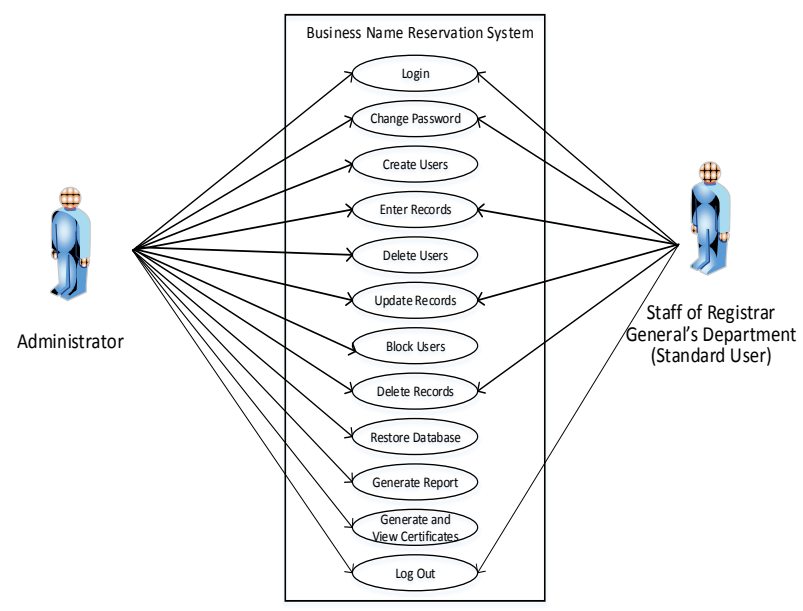

Fig 4: Use Case Diagram for Registration System

\subsubsection{Database Schema}

The diagram below, fig. 5 is a conceptual or semantic data model of the system. It is a relational database, and its requirements are presented in a top-down fashion.

\subsubsection{Sequence Diagram}

The system sequence diagram (SSD), fig.6 shows, for a particular scenario of a use case, the events that external actors generate, their order, and possible inter-system events.

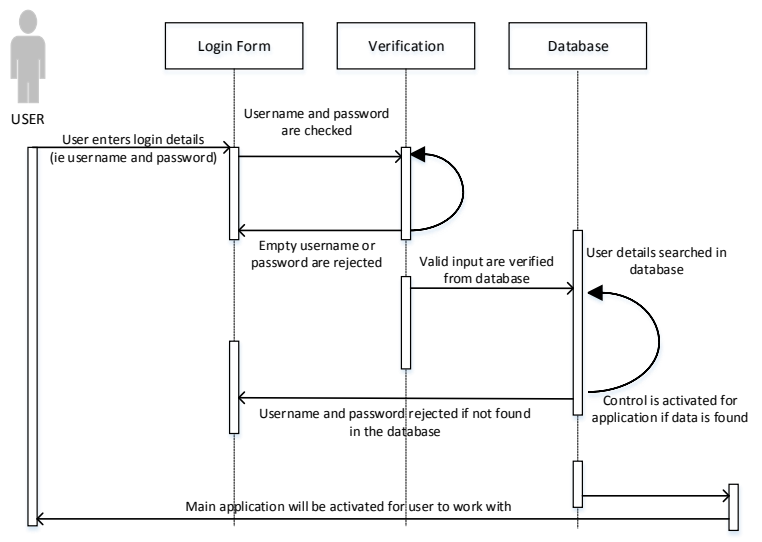

Fig 6: Sequence Diagram depicting the login process Database

\section{RESULT AND ANALYSIS}

As recommended by [13-14], for software system testing, a quality assurance test was conducted in order to correct bugs in the system and guarantee its optimum functionality. The testing was done using a hybrid of users from different backgrounds, ranging from people who are technology savvy and those who are not. This was done with the intention of ascertaining the level of ease with which potential users could learn and use the system. Despite, varied reactions were obtained from individual who carried out the test, greater majority of participants confirmed that it took less time to learn the system and use it.

Moreover, deployment of the application involved the installation of the finished product on a server and clients computers at the Registrar Generals Department. The required networking infrastructure was already setup so deployment and configuration of the system was much faster.
Various components of the application and their functionalities are depicted in the figures below

- Home Page:

Fig. 7 shows the main entry to the reservation section of the Registrar General's Departments website. This page gives a brief description of the services Registrar General's Department renders to the public. It also gives instructions on how to search and reserve business names.

\section{- $\quad$ Registered Business Names Page}

In fig.8, the page informs one whether the selected business name matches the selected search criteria or the chosen name is available for reservation. The "click here to continue reservation" link helps one to proceed to the actual page where the actual reservation is done.

\section{The Reservation Page}

The reservation page shown in fig.9, comes with the form that allows one to carry out the actual reservation of the chosen name. The form contains the necessary information required to be filled by the registrant to complete the reservation exercise.

\section{Print Page}

The print page shown in fig.9 is the last step of the reservation exercise. This document must be printed and submitted to the Registrar General's Department to continue the registration exercise.

\section{- $\quad$ Login Form}

The form presented in fig. 11 is the first form that users of the system interact with before actually gaining access to the main working environment. This section of the system is only accessed by the staff of Registrar General's Department.

\section{- The Registration Form}

The main form for registering new businesses and editing of existing ones is presented in fig. 12 .

\section{Registration Details Form}

The form presented in fig. 13 gives a grid view of all the businesses registered with the Registrar General's Department.

\section{Statistics Form}

The statistic form presented in fig.14 gives a pictorial representation of the activities carried out at the Registrar General's Department. It helps management in decision making.

\section{Report Form.}

The report generation functionality incorporated into the system and illustrated by fig. 15 helps administrators to generate reports based on certain criteria they specify and the sort of information they need at any point in time.

\section{CONCLUSION}

In summary, a system that is robust enough to withstand data inconsistency and handle data security issues have been created. Essentially, these qualities have been achieved through the following functionalities: data recovery, data encryption, audit trail, report generator, graph generator and notifications. 


\section{REFERENCES}

[1] Infosapp 2010. Registrar General's Department, Ghana. http://www.rgd.gov.gh/

[2] The World Bank Group. 2013. Doing Business. www.doingbusiness.org/data/exploreeconomies/ghana

[3] Altinn. 2010. Electronic Channel for reporting to Economic Life, Implementation Guide, Enterprise System Interface. http://www.altinn.no/webservices/MessageReceipt Exchange.

[4] Claus Hyllinge and Nicolai Lindgreen. 2010. Conflits between trademarks and Company and Business names. Report Q 155, Denmark

[5] The World Bank Group. 2011. Business Registration Case Study Norway. 1818 H Street N.W. Washington D.C, 20433.

[6] SmartCompany. 2012.Complaints Mount Over ASIC Business Name Register. http://www.smartcompany.com.au/legal/051056complaints-mount-over-asic-business-name-registerasic-admits-it-is-plagued-by-delays-and-technicalerrors-3.

[7] Andrade, J., Ares, J., García, R., Pacos, J. and Rodríguez and Silva, A. 2004. A methodological framework for generic conceptualization: problem sensitivity in software engineering. Information and Software Technology, Vol. 46, pp. 635-649.
[8] Avison, D.E. and Fitzgerald, G. 1999. Information systems development. Rethinking Management Information System.Oxford: Oxford University Press, pp. $250-278$.

[9] Barki, H., Oktamis, S. and Pinsonneault, A. 2005. Dimensions of ERP implementations and their impact on ERP project outcomes. Journal of Information Technology Management, Vol. 16 No. 1, pp. 1-8.

[10] Bhatt, G., Emdad, A., Roberts, N. and Grover, V. 2010 "Building and leveraging information in dynamic environments: the role of IT infrastructure flexibility as enabler of organizational responsiveness". Information \& Management, Vol. 47, pp. 341-349.

[11] Dix, A, Finlay, J., Abowd, G.D. and Beale, R. 2004. "Human-Computer Interaction". Essex. UK: Prentice Education Limited.

[12] Zang, X., Hu, T., Dai, H. and Li, X. 2010. "Software development methodologies, trends and implications: a testing centric view". Information Technology Journal, Vol. 9 No. 8, pp. 1747-1753.

[13] Mao, E. and Palvia, P. 2008. Exploring the effects of direct experience on IT use: an organizational field study. Information \& Management, Vol. 45, pp. 249-256.

[14] Markus, M.L. 2004. “Techno change management: using IT to drive organizational change. Journal of Information Technology", Vol. $19, \quad$ pp. 1-17. 


\section{APPENDIX A}

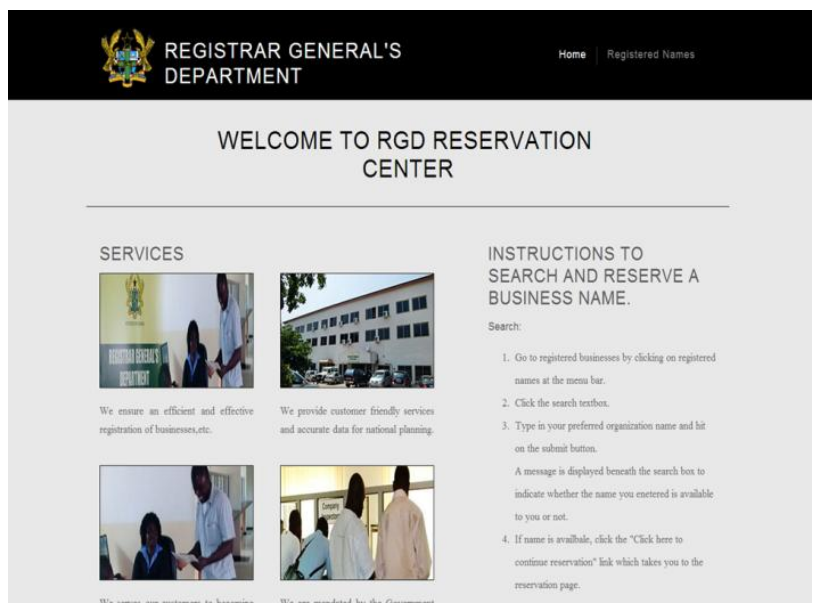

Fig 7: Screenshot of Home Page

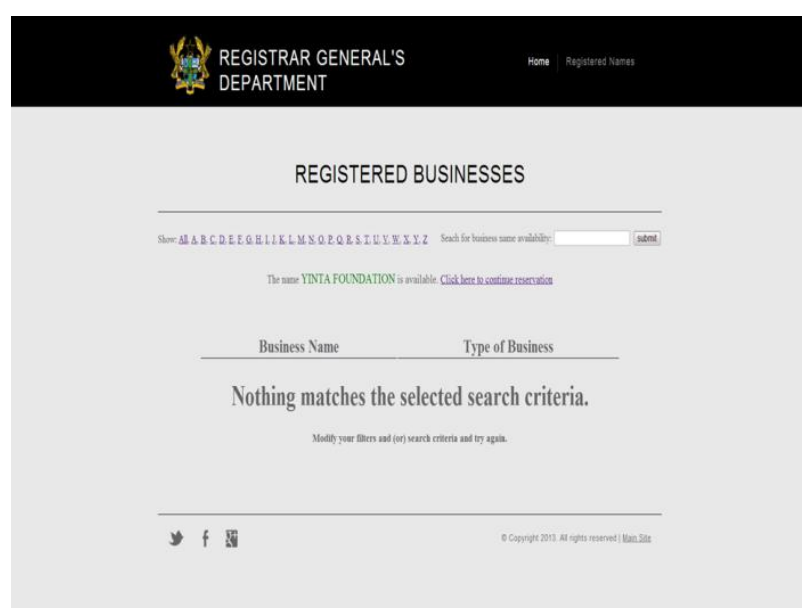

Fig 8: Screenshot Registered Business NamesPage

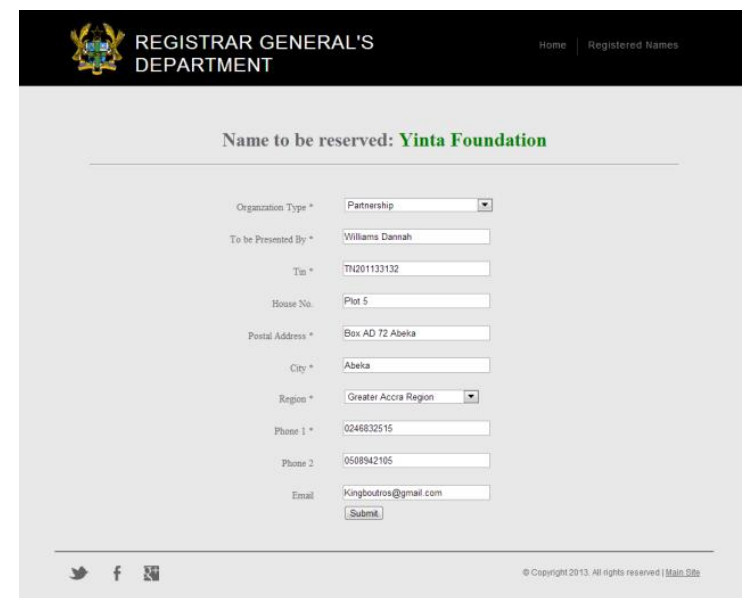

Fig 9: Screenshot of Reservation Page

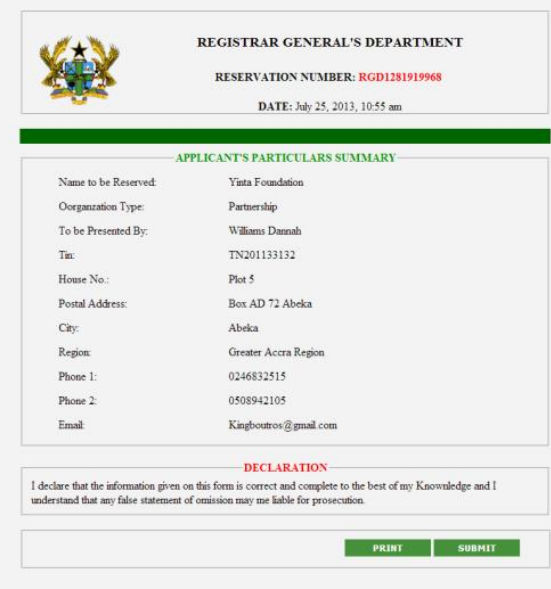

Fig 10: Screenshot of Print Page

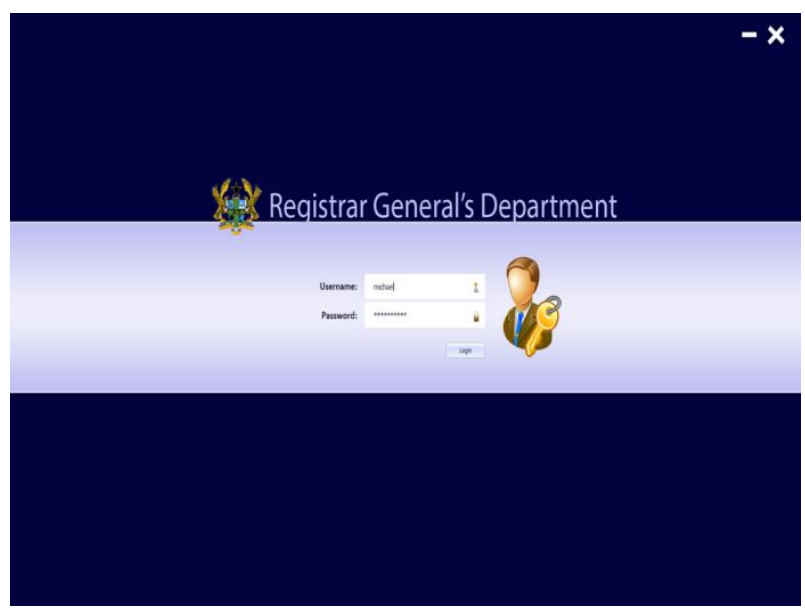

Fig 11: Screenshot of Login Interface

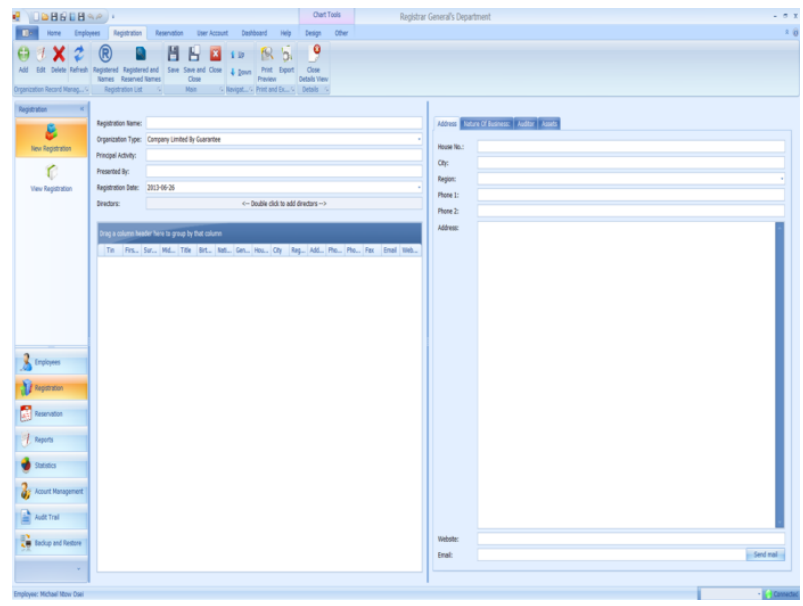

Fig 12: Screenshot of Registration Form 


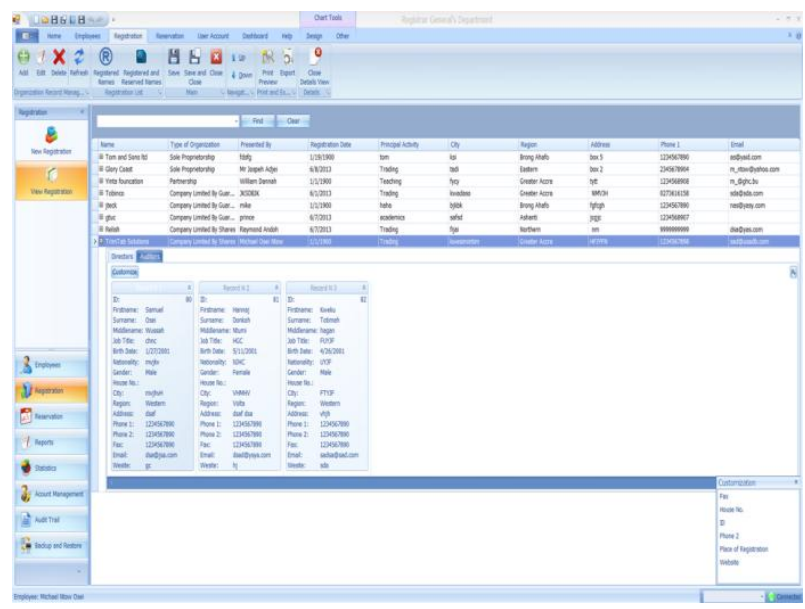

Fig 13: Screenshot of Registration Details

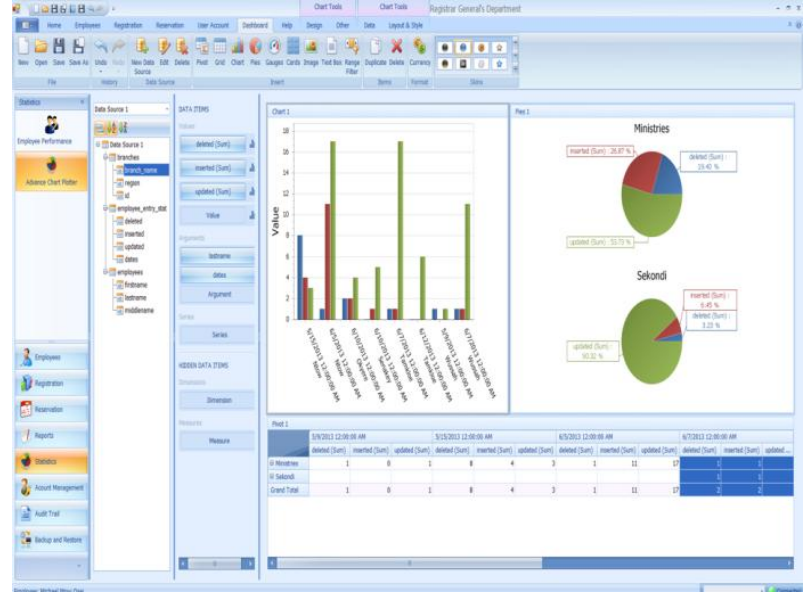

Figure 14: Screenshot of Statistics

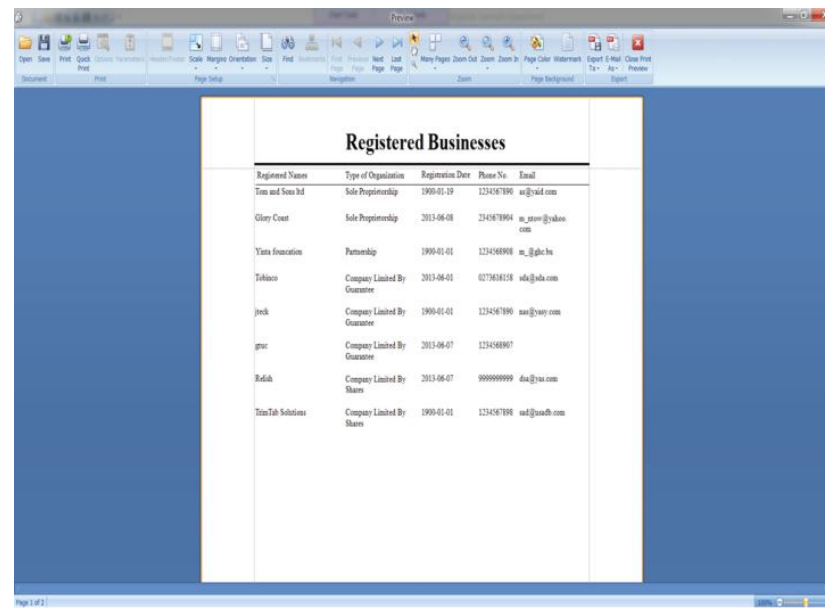

Figure 15: Screenshot of Report Form 


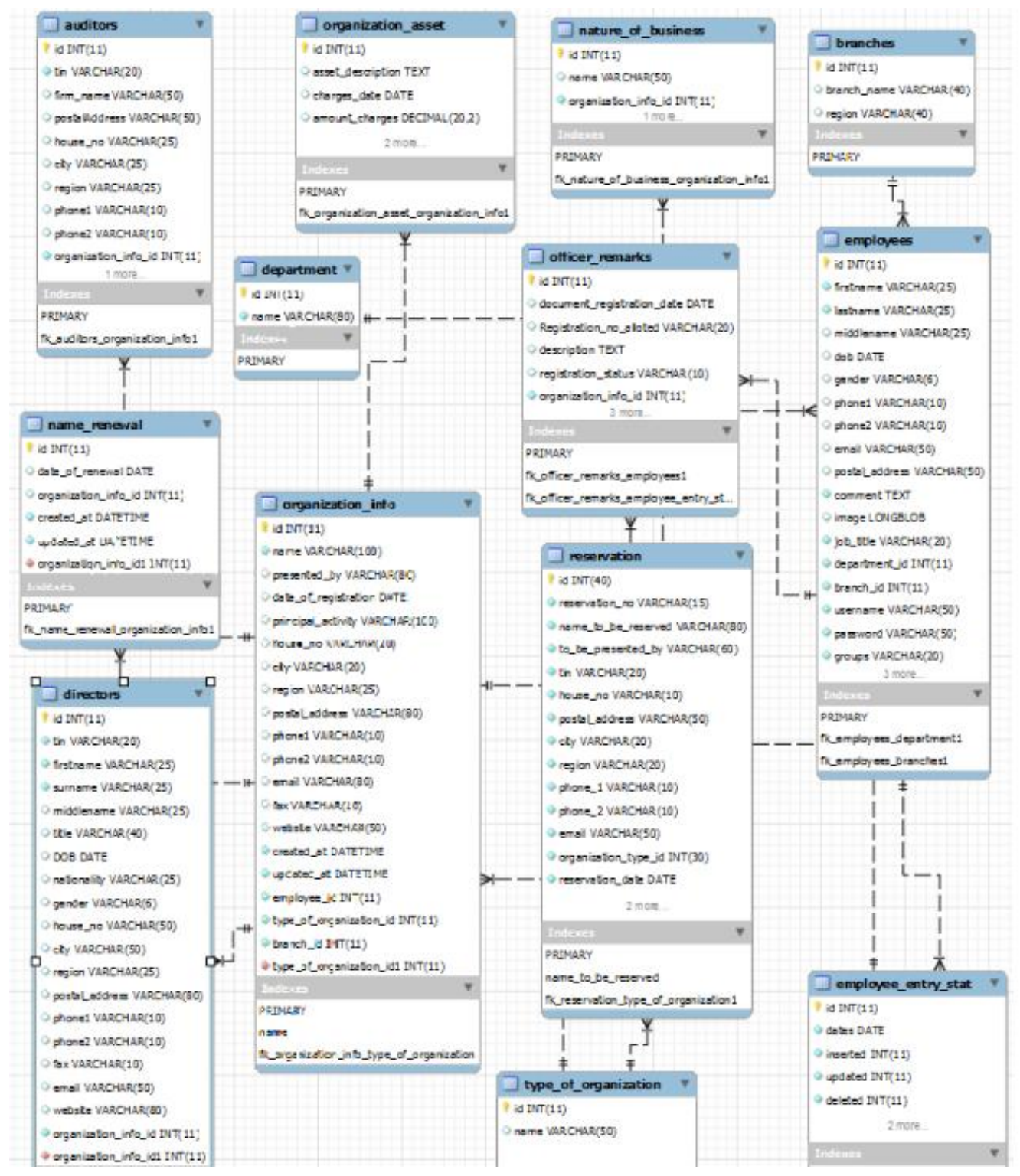

Fig 5: Database schema 